\title{
A Blended Module for the Emergency Medicine Resident: An Introduction to Vital Signs and Emergency Stabilization
}

\author{
Bobby Desai \\ Department of Emergency Medicine, University of Florida, Gainesville, USA \\ Email: bdesai@ufl.edu \\ Received 22 February 2015; accepted 12 March 2015; published 16 March 2015 \\ Copyright (@ 2015 by author and Scientific Research Publishing Inc. \\ This work is licensed under the Creative Commons Attribution International License (CC BY). \\ http://creativecommons.org/licenses/by/4.0/ \\ (c) (i) Open Access
}

\begin{abstract}
Beginning a residency in Emergency Medicine is a daunting task, and the new physician must be aware of what abnormal vital signs are and understand when to initiate emergency therapy. This module was created to teach the new physician about the vital sign of temperature. The module is blended to incorporate online learning via both direct and asynchronous methods, as well as faceto-face interactions using high fidelity simulation.
\end{abstract}

\section{Keywords}

\section{Blended Curriculum, Temperature, Emergency Medicine}

\section{Introduction}

Blended learning has been defined as "a wide variety of technology/media integrated with conventional, face-toface classroom activities" (Picciano, 2009). This definition can be applied to both courses and entire academic programs, including some Master's and Doctorate level courses (Laster, Otte, Picciano, \& Sorg, 2005). Important to note in blended learning is the fact that the objectives of instruction must drive the approaches that teachers must use in instructional activities. Furthermore, blending objectives with the use of multiple modalities may be the most effective means to reach a large range of students.

The primary driver of instruction is content. This can be delivered in multiple ways from traditional classroom pedagogies to novel online methods. Other areas that are important for this learning strategy include reflection (via blog or journal), collaboration (e.g. wiki), questioning (asynchronous discussion board), synthesis and evaluation (presentations, exams) and finally social and emotional support (face to face interaction). A good blended learning curriculum will include all of these factors (Kaleta, Skibba, \& Joosten, 2007). 
This module will focus on the application of these theories to the construction of a specific blended module, which can be tailored to specific uses.

\section{Context}

All residencies in medicine utilize a standard evaluation system in order to measure specific competencies with their resident housestaff. Over the years due to our changing health care system, the Accreditation Council for Graduate Medical Education (ACGME) is implementing an "outcomes-based evaluation system in which the doctors of tomorrow will be measured for their competency in performing the essential tasks necessary for clinical practice in the $21^{\text {st }}$ century" (The Next Accreditation System, 2013). All specialties in medicine will be transitioning to this new accreditation system in 2013. This new system will replace one that utilized six core competencies, which included professionalism, medical knowledge, practice-based learning, systems-based practice, communication, interpersonal skills, and patient care. This new system of milestones is predicated on "observable developmental steps moving from beginning resident to the expected level of proficiency at graduation from residency, ultimately, the level of expert/master” (Frequently Asked Questions, 2012). This systemin theory-is more objective than the old system, and thus presents academic faculty with the difficulty of how to assess the resident in terms of these milestones. The ACGME has provided suggestions for this, ranging from SDOT's (Standardized Direct Observation Tool), to simulation sessions, and checklists. Currently, there is no literature describing the best methodology for assessment, and thus the program is left to determine the means that would work for that specific program. The first category in the new Emergency Medicine milestone project is "Emergency Stabilization (PC1)". Due to the substantive nature of this milestone-basically, taking the just graduated medical student and making them an "expert/master"- this blended module focuses on the first level—recognition of abnormal vital signs.

\section{Background}

The initial milestone encompasses how the learner assesses a critically ill or injured patient and also how they recognize abnormal vital signs. Thus, this level is clearly focused on the beginner in perhaps the most difficult aspect of the specialty. The recognition of the sick patient is paramount in the specialty of Emergency Medicine and the physician must thus be eminently comfortable in the assessment of vital signs. Thus, this module was developed to satisfy the needs of the beginner, an early medical student ( $1^{\text {st }}$ and $2^{\text {nd }}$ year), as well as for those students on clinical rotations. It also serves as a refresher for interns.

\section{Past Experiences and the Learners Served}

Because the college of medicine is moving towards early clinical exposure for all medical students, these basic concepts must be taught earlier. Previously, it was assumed that all students knew how to obtain vital signs on their clinical rotations, but on many occasions this turned out not necessarily to be true. This is due to the fact that students were more engaged in the actual clinical practice of medicine, which ostensibly required more knowledge of the diagnosis and treatment of disorders; however, the basic required foundational knowledge seemed to be lost when transitioning directly into the clinical realm. In short, for the vital sign of temperature, a student couldn't even define what an abnormal temperature was, how it was obtained, pitfalls of the method the temperature was obtained, or ramifications of the abnormality. In the past, simulation based settings were primarily used to teach these concepts, and we had developed scenarios in which the recognition of abnormal vital signs was the key to the case. However, when we asked interns (most not from the University of Florida) to demonstrate the concepts of obtaining the vital signs, we found some of their knowledge lacking, as they were used to the nurse or technician obtaining the reading for them. From this, we learned that this error of omission was fairly universal among medical students throughout the country. Thus, this basic module was developed and can be utilized for medical students in their $1^{\text {st }}$ and $2^{\text {nd }}$ years in order for them to obtain this foundation of knowledge. This module is newly developed, and has never been used in the College of Medicine. This module is used primarily for interns - those that have just graduated medical school—in order to ensure that they have this knowledge within their diagnostic armamentarium. The overriding goal of this module is ensure that all interns working in the emergency department are on equal footing and can demonstrate knowledge of this fundamental concept. 


\section{Blending}

This module will have multiple modes, including:

1) An online module that presents basic information about vital signs and how to obtain them. This particular module concerns temperature measurement and the diagnosis and treatment of specific temperature related disorders. These modules are on the website linked at the beginning of the paper.

a) Time frame: 1 - 2 days.

2) Small group sessions discussing and demonstrating the concepts learned in the module.

3) A simulation based test to examine their knowledge of the content.

4) A community of inquiry to discuss concepts and lessons learned from this module, using for example, Google groups.

\subsection{Online Component}

The online module consists of a self-guided module building using Articulate Storyline. Storyline is an easy to use multimedia authoring tool that helps with the creation of interactive presentations. It incorporates quizzing in the created modules and allows for video recording as well. Audio can be embedded into the presentation and the built in templates allows for the rapid construction of a learning module. This software allows for output in multiple modalities. It can be delivered via the web, embedded in a SCORM (Sharable Content Object Reference Model) compliant LMS (Learning Management System), or within a website. For this module, files are delivered in a zip format to the learner.

The learner will utilize the module at their own pace and own time, usually least 2 days in order to adequately digest its content. With modules delivered in this format, learners can stop and rewind any section of the content at their leisure. Furthermore, within the module there are specific subsections with open ended questions. The learner should utilize these questions in order to ensure mastery of the content described within that particular section of the module. Furthermore, these questions will allow the reader to be prepared for the subsections further along. Once they have gone over the section on how to obtain a temperature measurement, the module progresses into pathophysiology which will subsequent dovetail into the small group sessions to follow.

\subsection{Small Group Sessions}

The small group sessions consist of a face to face meeting with students. Depending upon the number of learners and instructors, the group can be divided as required. This module has been utilized this particular format with groups of 1 - 8 students, but we have found that a group of 4 students is most ideal. During these small group sessions, the instructor will discuss the material learned in the online module and will go over the questions posed during each subsection of the online module. In this way these small group sessions will be interactive and participatory. The students will be shown the techniques of obtaining temperature, and the students will subsequently practice most of the techniques on each other with the instructor supervising. The students will thus be able to gain an ability to recognize the equipment utilized for techniques taught. Practicing on each other will allow them to practice the technique demonstrated by the instructor. For other techniques (rectal temperature), a mannequin can be utilized. Group discussion will include all concepts described in the module, especially the pathophysiology sections of the module. Mastery of concepts should be demonstrated by all learners on a mannequin, and this will comprise the assessment and evaluation portion of this section. A multiple choice test can be constructed and used to determine understanding of the pathophysiology concepts described in the online module. The evaluation can be done contemporaneously with the small group session or done with a larger group in a later setting.

\subsection{Simulation Session}

These sessions utilize high fidelity simulation mannequins. They are programmable, and with the aid of a technician, can be utilized for procedures as well. The fundamental difference between this activity and the small group session is that the learner will be provided with a specific scenario. They must utilize the knowledge gained from the module and interactions in the small group sessions and must be able to obtain a temperature specific for the situation while being led through a series of cases that are related to temperature disorders. They can simultaneously be evaluated and assessed. Any individual deemed to not have mastered the concepts must restart the module with the online component. 
Table 1. SDOT for simulation session.

\begin{tabular}{|c|c|c|c|}
\hline \multicolumn{4}{|c|}{ Emergency Stabilization } \\
\hline 0 & 1 & 2 & 3 \\
\hline $\begin{array}{l}\text { Not quite } \\
\text { intern level }\end{array}$ & $\begin{array}{l}\text { (At Intern level) } \\
\text { Recognizes abnormal vital }\end{array}$ & $\begin{array}{l}\text { Above intern } \\
\text { level }\end{array}$ & $\begin{array}{l}\text { (Solid } 2^{\text {nd }} \text { yr) Recognizes the unstable patient who needs immediate } \\
\text { intervention. } \\
{ }^{*} \text { Prioritizes initial stabilization actions in a resuscitation } \\
{ }^{*} \text { Performs a primary assessment on a critical patient }\end{array}$ \\
\hline \multicolumn{4}{|c|}{ Performance of Focused History \& Physical Exam } \\
\hline 0 & 1 & 2 & 3 \\
\hline $\begin{array}{l}\text { Not quite } \\
\text { intern level }\end{array}$ & $\begin{array}{l}\text { (At intern level) Performs and } \\
\text { communicates a reliable, } \\
\text { comprehensive H\&P }\end{array}$ & $\begin{array}{l}\text { Above intern } \\
\text { level }\end{array}$ & $\begin{array}{l}\text { (Solid } 2^{\text {nd }} \text { yr) Performs and communicates a focused H\&P reliably } \\
\text { addressing the chief complaint and urgent issues }\end{array}$ \\
\hline \multicolumn{4}{|c|}{ Diagnostic Studies and Performance of Required Procedures } \\
\hline 0 & 1 & 2 & 3 \\
\hline $\begin{array}{l}\text { Not quite } \\
\text { intern level }\end{array}$ & $\begin{array}{l}\text { (At intern level) Determines } \\
\text { necessity and Urgency of } \\
\text { diagnostic studies }\end{array}$ & $\begin{array}{l}\text { Above intern } \\
\text { level }\end{array}$ & $\begin{array}{l}\text { (Solid } 2^{\text {nd }} \text { yr) Prioritizes essential testing \& orders appropriate tests } \\
\text { using decision rules } \\
{ }^{*} \text { Performs appropriate bedside diagnostics }\end{array}$ \\
\hline \multicolumn{4}{|c|}{ Diagnosis } \\
\hline 0 & 1 & 2 & 3 \\
\hline $\begin{array}{l}\text { Not quite } \\
\text { intern level }\end{array}$ & $\begin{array}{l}\text { (At intern level) Constructs } \\
\text { ddx based on cc \& initial } \\
\text { assessment }\end{array}$ & $\begin{array}{l}\text { Above intern } \\
\text { level }\end{array}$ & $\begin{array}{l}\text { (Solid } 2^{\text {nd }} \mathrm{yr} \text { ) Constructs ddx based on the greatest likelihood of } \\
\text { occurrence and greatest potential for harm. } \\
\text { "Correctly identifies "sick versus not sick" }\end{array}$ \\
\hline
\end{tabular}

\subsection{Reflections}

Using a wiki site set up by the instructor, the learners will write reflections of the module and how it has changed their practice. This will also serve as a course evaluation.

\section{Assessment}

The online component does not have any specific assessment tools, but they can be easily placed within the confines of the modules. Multiple choice, true-false or picture based questions can be utilized without difficulty. The software will grade the answers and the learner will have instant feedback.

The small group sessions will have the procedures demonstrated by the learners on a mannequin which would be available during the course. Individual responses need not necessarily be evaluated at this time, but group participation can easily be noted and placed within the confines of a formative evaluation

Finally, the simulation session will be assessed using an SDOT (Standardized Direct Observational Assessment Tool) developed for the course. This SDOT has been successfully utilized for intern level learners and can be easily modified for $3^{\text {rd }}$ and $4^{\text {th }}$ year medical students. For those $1^{\text {st }}$ and $2^{\text {nd }}$ year students, this should be substituted with contemporaneous feedback and a formative evaluation. See Table 1 for SDOT.

\section{Conclusion}

This module is an example of a blended curriculum that can be easily designed and implemented for any residency program to use. It is easily modifiable and its basic skeleton can be modified to assess other vital sign components, including blood pressure and pulse.

\section{References}

Frequently Asked Questions about the Next Accreditation System (2012). http://www.acgme-nas.org/assets/pdf/NASFAQs.pdf

Kaleta, R., Skibba, K., \& Joosten, T. (2007). Discovering, Designing, and Delivering Hybrid Courses. In A. G. Picciano, \& C. Dzuiban (Eds.), Blended Learning: Research Perspectives. Needham, MA: The Sloan Consortium. 
Laster, S., Otte, G., Picciano, A. G., \& Sorg, S. (2005). Redefining Blended Learning. Presentation at the 2005 Sloan-C Workshop on Blended Learning, Chicago, IL, 18 April.

Picciano, A. (2009). Blending with Purpose: The Multimodal Model. Journal of the Research Center for Educational Technology, 5, 4-14.

The Next Accreditation System: Frequently Asked Questions (2013). http://www.acgme-nas.org/nas-faq.html 